\title{
Translators' Subjectivity in Literary Translation: From the Perspective of Reader-Reception Theory
}

\author{
Hongmei Yang and Suling Qi \\ Sichuan Technology and Business University, China \\ Southwest Jiaotong University Press, China \\ maggyyang@163.com,179965210@qq.com
}

Keywords: Reception; Horizon of expectation; Subjectivity; Strategy

\begin{abstract}
On the basis of reception theory, the paper probes into the variety of translation strategies from the process of literary translation, indeterminacy of text meaning, horizon of readers' expectation and translators' foregrounding. And then the translator's subjectivity is also discussion from the perspective of reception theory. At the same time, the adjustment of translators' strategies is still bound up with the original text.
\end{abstract}

\section{Introduction}

In 1960s, based on phenomenology and philosophical hermeneutics, Hans Robert Jauss and Wolfgang Iser, the outstanding representatives of the Constance school, founded the Reception Theory, which is also known as Reception Aesthetics. The theory has changed the objective meaning of literary reading in the light of the indeterminacy of literary text and the specific strategies of the reader. It starts from the diversity of understanding and the reality of literary polysemous phenomenon, and breaks through the barriers of the authors and works in traditional literary theory research as well. For the first time from the height of ontology the readership and acceptance issues overlooked are presented, which emphasizes the reader's main role in the process of literary text reading. The acceptance process means the creation process of the text, but only this process can make the literary text achieve its real life. In addition, as the subject of reception, each reader has a unique relationship with the text. That is to say, different readers will have different understanding of the text and respond to the text differently because the original text is not a not a self-value entity, but a different object for different readers. Therefore, the interpretations of a literary text are bound to be different, and sometimes even greatly different. And the differences result from the imagination of different readers, which embodies the indeterminacy of the text with different meanings and specific approaches. However, since the translator is the first reader of the source text, the reception theory is undoubtedly applicable to the translator's translation strategies.

\section{The Process of Literary Translation}

According to traditional translation theory, the translation should coincide with the original text perfectly and translation is the reproduction of the original text by the translator. Based on this understanding, it is easy for people to idealize the translation, ignoring the translator's active participation in the interpretation of the original text. Thus, the translator will make efforts to pursue the perfect coincidence of the original text and the source text in translation. As a result, some concepts such as "faithfulness, expressiveness, elegance", "perfection" and "equivalence" and "equivalent" appeared in theory. Meanwhile, in practice, to a certain extent it will also mislead the translator, so that the translator may face the embarrassment of imbalance situation, and even counterproductive consequences.

In fact, after a careful observation, it is not difficult to find out that the text we translate is not the original text indeed, but rather an approximate Text or a virtual text produced by the translator in the process of communication with original text. Obviously, our version comes directly from the approximate or virtual text. It is the result of communication between the translator and the text and 
also the result of "Fusion of Horizon." This approximate or virtual text is variable, which varies due to different translators and different time and space.

In literary text, linguistic form has not only a text-cohesive, but also an aesthetic function; it carriers the creative will of the artist, and this lends the literary text an outward appearance which, in principle, can never be repeated and can therefore be realized in the TL only in analogous form. Hence, literary translation is an art, not a craft. (Wills, 1982:77) According to Wills, a good translation is closely connected with the imagination and creation of the translator.

\section{The Indeterminacies of the Text}

Jauss thought acceptance of literary text is a kind of interpretation, and the meaning of the works is what the reader explores from the text of the work, which contains a lot of "blanks" or "indeterminacies". Only in the specific activities of readers in reading process, these "blanks" or indeterminacies" can be filled or described, so the significance of the work is not inherent in the text, but generates from the reader's specific reading process. The reader should compare every work with the formers he has read before to regulate the present acceptance when reading a new work. And then his or her understanding of the works constitutes the existence of the works. Each specific reading is a conscious adjustment of history and reality.

For Iser, meaning is not an object to be found within a text, but is an event of construction that occurs somewhere between the text and the reader. A literary work, which for Iser is created when a reader and a text "converge, consists of two "poles": the artistic (the object, the text created by the author) and the aesthetic (the realization accomplished by the reader). (Iser, 1978:36) According to his Response-inviting Structures, the convergence of the text and the reader makes the real existence of literary works, and the meaning of the text depends on the creativity of readers. The active participation of readers is an important factor in the interpretation of the text of the potential significance.

As a reader begins the reading process, the sentences that make up a work not only inform the reader of the literary movement, but produce certain expectations within the mind of the reader.(Iser,1972:282) However, these expectations are rarely fulfilled, as a text is "full of unexpected twists and turns, and frustrations of expectations...Thus whenever the flow is interrupted and we are led off in unexpected directions, the opportunity is given to us to bring into play our own faculty for establishing connections-for filling in the gaps left by the text itself." (Iser, 1972:285) These gaps are the unwritten portion of the text that calls for the reader's participation. Different readers will decide to fill in the various gaps in different ways, allowing for inexhaustible realizations of the text within its provided interpretive limits. As the reader reflects on what they have read previously in the text, or if they reread the text, new light is shed on the happenings within the narrative as "certain aspects of the text will assume a significance we did not attach to them on a first reading, while others will recede into the background." (Iser, 1972:286)

For example, Henry Fielding described the picture of Andrew's first time to London with his master: "His hair was cut after the newest fashion. (H. Fielding, 1970:22)" In the novel, the author tells the reader Andrew wore the most fashionable hair, but the reader doesn't know the style and the color of the hair. So the reader can fill the "blank" reasonably with his or her imagination, named "spots of indeterminacy" by R. Ingarden. In literary works, however detailed or elaborate the authors describe something or somebody, there is always something that needn't description, which gives the reader the space of imagination. Just as $\mathrm{Lu} \mathrm{Xu}$ said, This is the unique aesthetic psychology of different readers or expectations of vision, driven by its unique way to grasp the results caused by the same work.

\section{The Target Reader's Horizon of Expectation}

The so-called "horizon of expectations", refers to the original reader's experience, taste, quality, ideal and the comprehensive appreciation of literary works, level and vision in the literary reception activities. And it is a kind of aesthetic potential in the specific reading performance. People always 
exist in history, and the understanding of human beings cannot eliminate the historical particularity and historical limitations. However, hermeneutics believes that interpretation is to constantly expand and beyond their original vision, and the historical text reach the fusion, to overcome the previous understanding of the constraints, and to generate new knowledge. "Literature is not an object that provides the same look to every observer of every era. It is not a monument that shows its eternal nature alone. On the contrary, it is more like a piece of music, constantly hitting new music in reading".(Jauss, 1982:21).

The coherence of literature experience as an event is primarily mediated in the horizon of expectations of the literary experience of contemporary and later readers, critics, and the authors. Whether it is possible to comprehend and represent the history of literature in its unique historicity depends on whether this horizon of expectations can be objectified (Jauss, 1982:78).

In translation, taking the target language readers' horizon of expectations and the ability to accept into account, in a certain period of time the translator will adopt domesticating translation, but the implied deep culture in the text is difficult to be swallowed up, and all the exotic always more or less is conveyed to the readers through translation. With the reader's understanding of the foreign cultures, their expectation of foreign literary works and the expectation of the exotic life are changing, while the translators are not indifferent to these changes. Just as the original author, the translator will always take into consideration the changing expectations and aesthetic expectations of the target audience, and adopt appropriate translation strategies such as domestication and foreignization.

Take the translation of Shakespeare' poem for example. 'Shall I compare thee to a summer's day? Thou art more lovely and more temperate. Rough winds do shake the darling buds of May, And summer's lease hath all too short a date," There are over 10 versions of translation about this Shakespeare's sonnet. We cannot judge which version is good or which one is bad. Each one has different varieties and types. The first version is easy, smooth and graceful, while the second and the third are contemporary and vernacular. Maybe it is the requirement of the time, and maybe it is the natural choice of the translator. When translating, the translators will fill the blank based on their own understanding of the original text, their own aesthetic experience, and their knowledge and expectations. Even during the same period, because of the different levels of reception, the translator's understanding of the original text is different, which causes different ways of filling of the original blanks. And because of the limitations of history, the translators of different times have different levels of reception, and their ways of filling the gap are even more different.

\section{The Translator'S Historicality of Comprehension}

The history of modern philosophical hermeneutics emphasizes the understanding of history. They believe people are always there and everyone will take his own life experience, knowledge, cultural awareness and ethics into the interpretation process. The subject and object of interpretation are embedded in the history, and then the real understanding is not to overcome the limitations of history, but to evaluate it correctly. Understanding is always understanding in a certain historical stage, and different interpreters will have a dialogue with the text with different foregrounding, so the meaning of the text will inevitably lead to the emergence of diversity. Therefore, in the process of translation, as the first reader of the original text, the translator's the interpretation of the original text is historical undoubtedly. Therefore it is impossible for anyone to prove that his understanding of the original paper fully complies with the author's original intention. To achieve a complete "faithfulness" or "equivalence" is just a perfect ideal. For instance, in the late Qing Dynasty, with the invasion of foreign powers, the Chinese nation was in the domestic trouble and foreign invasion. In that special historical period, the translation of political novels became popular. Some translators even added "political sense" into the original novels without political color, through which they conveyed the political thought of opposing feudal autocracy, striving for national independence, democracy and freedom to Chinese people. To some extent, it reflects the translator's subjectivity.

For example, Chinese classic novel "The Water Margin", Shapiro's translation was Outlaw of the Marsh, while Pearl. S Buck translated All men are brothers. Because they two had different 
understanding of this classic novel, they translated it differently. "Shuihu Zhuan" focuses on the adventures of Song Dynasty, outlaw Song Jiang and companions, a band of Robin Hoods who led rebellious campaigns against a corrupt government. At the time of the Cultural Revolution, these bloody fables raised uncomfortable analogies that soon drew the attention of Jiang Qing. Jiang Qing didn't want Song Jiang painted as a hero, so Shapiro had to change the title "Heroes of the Marsh" to "Outlaw of the Marsh". In the end, Jiang Qing's people agreed, blissfully unaware that in English "outlaws" are thought of more as folk heroes than criminals. It was by exploiting this ambiguity that Shapiro was able to keep both his head and his integrity. Because of different background and experience, Shapiro and Pearl translated this novel quite differently even though their versions are classic.

\section{Conclusion}

The translators of different historical periods cannot exhaust the text connotation one time because of the historical limitations of understanding, so the interpretation of the text is only a step closer to the aesthetic value of the original process. The negativity of the text, the change of the reader's expectations and the translator's historical understanding all put the translator's status into the foreground. Both the translator and the original author construct different cultures in their respective cultural context. The translator shall not dance with shackles any more, but have the right to adjust the translating strategies within the limits. Therefore, it is of great significance to display the translator's subjectivity.

\section{Bibliography:}

[1] Iser, Wolfgang. (1978) The Act of Reading: A Theory of Aesthetic Response. Baltimore: The

[2] Johns Hopkins University Press.

[3] Iser, Wolfgang. (Winter, 1972)The Reading Process: a Phenomenological Approach, New

[4] Literary History, Vol. 3, No. 2, On Interpretation: p282-296.

[5] Jauss, Hans Robert. (1982) Aesthetic Experience and Literary Hermeneutics. Trans, Michael

[6] Shaw. Minneapolis: University of Minnesota Press.

[7] Jauss, Hans Robert. (1982) Toward an Aesthetic of Reception. Trans, Timothy Bahti.

[8] Minneapolis: University of Minnesota Press.

[9] Jauss, Hans Robert. (1967) New Literary History: Literary History as a Challenge to Literary

[10] Theory, Baltimore: The Johns Hopkins University Press pp. 7-37

[11]Zhu Liyuan, (2014) Contemporary Western Literary Theory, Shanghai: East China Normal University Press

[12] Terry Eagleton, (2007) Western Literary Theory in the 21st Century, translated by Wu Xiaoming. Beijing: Beijing University Press.

[13] Hans Robert Robert, R. C. Hora, (1987). Accepting Aesthetics and Reception Theory, Zhou Ning, Jin Yuanpu Translation. Shenyang: Liaoning People's Publishing House.

[14] Ma Jingbo $(2004,2)$ Translator's Subjectivity, Journal of Yanshan University 